\title{
YAPAY ZEKA İLE BİR EĞLENCE YAZILIMI: BENZEDİĞİN ÜNLÜ KİM?+
}

\author{
**** \\ AN ENTERTAINMENT SOFTWARE WITH ARTIFICIAL \\ INTELLIGENCE: WHICH CELEBRITY DO YOU LOOK LIKE?
}

\begin{abstract}
$\ddot{\mathbf{O} z}$
Dijital çağda kullanılan yapay zekâ teknolojileri, tüm sektörlerde olduğu gibi dijital eğlence sektöründe de müşteri odakl olarak hızlıca yapılandırılan kişiselleşmiş ürünlerin gelişmesine firsat vermiştir. Bu kişiselleşmiş ürünler kısa süreli aidiyetler, üstgerçeklik, anlık tüketim hazları sağlama gibi dijital çağın postmodern istekleri gözetilerek oluşturulmaya çalışılır. Bu çalışma da, bu istekler gözetilerek hazırlanan ve gerçek zamanlı olarak oynanabilecek bir eğlence yazllım metodolojisi sunmaktadır. Hazırlanan uygulama çalıştığında, kameradan elde edilen yüz görüntüsü, bu yüze en çok benzeyen ünlünün yüz görüntüsü ve bu iki yüz arasında bir ara yüz görüntüsü ekranda görüntülenmektedir. Çalışmada kameradan elde edilen görüntüden gerçek zamanlı olarak yüz görüntüsünün bulunması için haar peşpeşe sinıflandırıcılarından faydalanıldı. Sonra elde edilen yüz görüntüsünün, eğitimde kullanılan ünlü yüz görüntüleri ile karşılaş̧ırılması için özyüzler yöntemi kullanıldı. Son olarak görüntü işleme teknikleri kullanılarak ünlü ve kullanıcı yüzlerinin her ikisine de benzeyen bir yüz görüntüsü oluşturuldu. Böylece çalışmada, yaygın kullanılan yapay zeka algoritmalarıla gerçek zamanl olarak oynanabilecek ve farklı obje benzerlikleriyle çeşitlendirilebilecek bir kişiselleştirilmiş eğlence uygulama metodolojisinin sunulmaya çalışıldı.
\end{abstract}

Anahtar Kelimeler: görüntüsel benzerlik, yapay zeka, sanal gerçeklik, dijital eğlence, özyüz yöntemi, haar paşpaşe siniflandirıcılar

\begin{abstract}
Artificial intelligence technologies in digital age have given the opportunity to develop customized products that are quickly structured in a customer-oriented manner in the digital entertainment sector as in all sectors. These personalized products are tried to be created by taking into account the postmodern demands of the digital age, such as short-term affiliations, hyperreality, instant pleasures. This study presents an entertainment software methodology that is prepared according to these demands and can be played in real time. When the prepared application runs, the face image obtained from the camera, the face image of the most similar celebrity to this face and a face image between these faces are displayed on the screen. Haar cascade classifiers are used to find real-time face image from the image taken with the camera. Then the eigenface method is used to compare the obtained face image with the famous face images used in education. Finally, using image processing techniques, a face image similar to both celebrity and user faces is created. Thus, in the study, it is tried to present a personalized entertainment application methodology that can be played in real time with widely used artificial intelligence algorithms and can be diversified with different object similarities.
\end{abstract}

Keywords: image similarity, artificial intelligence, virtual reality, digital entertainment, eigenface method, haar cascade classifier

\footnotetext{
+ Bu çalışma, 9-11 Aralık 2020 tarihlerinde, IMISC 2020 Sempozyumunda sözlü bildiri olarak sunulmuştur.

* Dr. Öğr. Üyesi Çağla Ediz, Sakarya Üniversitesi, İşletme Fakültesi, Yönetim Bilişim Sistemleri Bölümü, ediz@ sakarya.edu.tr ORCID: 0000-0002-0793-3722
} 


\section{GİRiș}

İnsanın duyularıyla birleşerek gerçeklik hissi veren görseller, sesler ve hatta dokunma hissi verebilen efektlerden oluşan sanal gerçeklik, gerçeküstü yaklaşımı beraberinde getirebilmekte ve rüyanın büyük gücünü ortaya çıkarmaktadır (Türker, 2005). İlk sanal gerçeklik çalışmalarının tarihte mağara resimleri ile başladığ kabul edilse de (Sherman ve Craig, 2019); teknolojinin gelişmesiyle sanal gerçeklik, kullanıcıyı izleyen ve kullanıcı hareketlerine göre tepki veren bilgisayar teknolojilerine dönüşmüştür (Erkılıç ve Can Dönmez, 2020). Bilgisayar teknolojilerinin kullanımının yaygınlaşması ve ucuzlaması, sanal gerçekliğin oyun ve eğlence alanında da kullanılabilmesini sağlamıştır. Buna ilave olarak, eğlencenin insanlara fiziksel ve psikolojik rahatlama vaat ederken onları tüketime yönlendirebilmesi onu bir endüstri kolu haline getirilmiş ve böylece eğlence sektörü oluşturulmuştur (Varol, 2012). Teknolojinin gelişmesi beraberinde küreselleşmeyi ve büyük bir rekabet ortamını da getirmiş, bunun neticesinde üretim ve hizmet sektörlerinde insan odaklı pazarlama anlayışı hakim olmuştur. Teknolojinin yaygınlaştığı bu dönemde, tüketicinin yerini aklı, kalbi ve ruhuyla hareket eden bireyin aldığını kabul eden firmalar, bireysel talepleri anlayacak ve hızlı bir şekilde bunları karşılayabilecek adımlara yönelmişlerdir (Kotler vd, 2016). Ayrıca bu dönemde, şirketler müşterilerin geleneksel ihtiyaçlarını ve beklentilerini yerine getirmeye çalışmakla birlikte, müşterilerin ürünün kendisine etki edebileceği çözümler geliştirmeye çalışmışlardır. İnternetin ve bilgi işleme sistemlerinin gelişmesiyle postmodern tüketici davranışlarını sergileyen tüketiciler, postmodern anlayışla zıtlıkların birlikteliğine tolerans göstermişler, farklı sosyal gruplarda farklı kimliklere bürünmüşler, daha kısa süreli deneyimlere yönelmişler, içerikten çok biçime değer vermişler, simülasyona dayalı temsillerle gerçek ötesini bir başka ifadeyle üst gerçekliği yaşamışlardır (Özbay, 2020). Postmodern dünyadaki tüketici, yaşamak zorunda kaldığımız gerçek yerine yaşamayı arzu ettiğimiz sanal dünyayı tercih edebilmekte; imaj, taklit ve simülasyon gerçeğin yerini alabilmektedir (Bozkurt, 2016). Son dönemde insan odaklı pazarlama anlayışı korunarak Endüstri 4.0 ile bir sonraki aşamaya ilerlenmiş ve dijital pazarlamaya geçiş başlamıştır. Dijital pazarlamada gerçek zamanlı verilere ulaşılır, farklı kanallardan müşteriler, ürünler ve sistemler izlenir, bu veriler yapay zekaya dayalı sistemler aracılığıyla işlenir ve sibernetik sistemlerle değerlendirilerek refleks mekanizmalar oluşturulur. Bu kapsamda dijital eğlence sektöründe de, kullanıcıların ilgisini çekmek, onları daha uzun süre sosyal medya ortamlarında tutabilmek gibi amaçlarla, yapay zekaya dayalı farklı eğlence yazılımları kullanıcılara sunulmaktadır. Postmodern tüketicinin istekleri gözetilerek hazırlanan yazılımlarda, kullanıcıların farklı özellikleri anlık sayılabilecek kısa bir zaman diliminde değerlendirilmekte ve hızlı bir şekilde onlar için kişiselleştirilmiş çıktılar oluşturulmaktadır. Bu tür yazılımlar, eğlence görevinin yanı sıra kullanıcılarına ilgilenildiklerini ve önemli bir kişi olduklarını hissettiren (Şener, 2012) ve akıllı telefonlar aracılığıyla rahatça ulaşılabilen sosyal medya platformlarında gittikçe yaygınlaşmaktadır. Örneğin, sosyal medyada eğlence ve görünürlüğü sağlama amacıyla kullanılan bazı uygulamalar, kullanıcı fotoğraflarına göre farklı görsel çıktılar sağlamaktadır. "Yaşlandığında nasıl görüneceksin?”, "Hangi ünlüye benziyorsun?", "Kızdığında hangi hayvana benziyorsun?" gibi sorulara cevap verecek şekilde görseller oluşturan bu uygulamalar sosyal medyada ilgi çekmekte ve paylaşılmaktadır. Bu tür eğlence amaçlı hazırlanan uygulamaların daha gerçekçi sonuçlar vermesi daha çok ilgi görmesine ve daha çok paylaşım yapılmasına katkı sağlayacaktır. Bu çalışmada eğlence amaçlı kullanılan ve yukarıdaki sorulara cevap veren uygulamaların hazırlanması için bir yöntem sunulmuş ve uygulamada daha gerçekçi sonuçların alınabilmesi için, dijital çağın bir çıktısı olarak görülen yapay zeka algoritmalarından (Taşçı ve Çelebi) faydalanılmıştır. Böylece, çok düşük bir maliyetle, bir insanın kısa sürede hesaplamasının imkansız olduğu kadar fazla sayıda işlemlerle anlık sayılabilecek bir zaman diliminde ve en optimum çözümle işlem yaptığı kabul edilen yapay zekayı kullanarak sanal gerçeklik oluşturan bir eğlence yazılım metodolojisinin sunulması amaçlanmıştır.

$\mathrm{Bu}$ çalışmada kullanılan metodoloji benzer görüntülerin eşleştirilmesini sağlamaktadır. Benzer görüntülerin bulunması ile ilgili literatür çalışmalarına bakıldığında, farklı yöntemlerin 
uygulandığı görülmektedir. Bu çalışmalardan biri olan $\mathrm{Li}$ ve diğerlerine (2014) ait çalışmada kırpma, kaydırma, ölçeklendirme gibi metotlar kullanılarak orijinal görüntülere benzer görüntüler elde edilmiştir. Sonrasında kontrasta dayalı algoritmalarla içerik analizi yapılmış, içeriklerdeki nesneler orijinal görüntülerdeki nesnelerle eşleştirilmiş ve ardından görüntülerdeki uzaklık hesaplama, köşe kullanımı gibi analizlerle deformasyon tespitleri yapılmıştır. Benzerlikle ilgili bir başka çalışmada ise, insan yüzlerinden akrabalık iliş̧kileri bulunmaya çalışılmıştır (Fang vd., 2010). $\mathrm{Bu}$ çalışmada renk özelliği ve yüz bölgelerine ait ölçüsel özellikler çıkarılarak ebeveyn-çocuk ilişkileri bulunmaya çalışılmıştır. Hazırlanan çalışmada benzerlik ilişkisi, kameradan elde edilen kullanıcının yüz görüntüsüyle, seçilen ünlü kişilere ait kaydedilen yüz görüntüleri arasında kurulmaya çalışılmaktadır. Benzerlik kurulurken literatürdekilerden farklı olarak özyüzler yöntemi uygulanmış ve kullanıcının oynarken eğleneceği bir uygulama geliştirilmeye çalışılmıştır. Özyüzler yöntemi, yüze ait renk değerlerini bütünsel olarak değerlendirmekte ve boyut düşürerek özellikler oluşturmaktadır. Kullanıcıya ait test görüntüsüne en benzer olan ünlü kişiye ait yüz görüntüsü bulunduktan sonra da, bu iki görüntü birleştirilerek bir ara yüz görüntüsü elde edilmektedir. Böylece, hem kullanıcı yüzüne hem de ünlü kişiye ait yüz görüntüsüne çok benzeyen bu ara yüz görüntüsüyle benzerliğin daha ikna edici olmasının sağlanması hedeflenmektedir.

Çalışmanın ikinci bölümünde yüz tespiti için kullanılan yöntemler sırasıyla anlatılmıştır. Üçüncü bölümde tespit edilen yüzün ünlü yüz görüntüleriyle karşılaştırılması amacıyla hazırlanan eğitim ve test aşamalarında seçilen metodolojilerin içeriği anlatılmıştır. Dördüncü bölümdeyse denemelerden elde edilen bulgular incelenmiştir. Böylece, kullanıcıyı bekletmeden hızlı ve aynı zamanda ikna edici bir üst gerçeklik görselliği ile kullanıcıyı ünlü birisiyle özdeşleştirerek kullanıcıya anlık hazlar sağlayan bir eğlence uygulama metodolojisi sunulmuş ve benzer eğlence uygulamalarının da bu metodolojinin kullanılarak geliştirilebilmesi amaçlanmıştır.

\section{YÜZ TESPITI VE METODOLOJISİ}

Hazırlanan yazılımda yüz tespit işlemi için ilk önce kameradan elde edilen görüntü, siyah beyaz görüntüye dönüştürülür. Çünkü siyah beyaz bir görüntü, renkli bir görüntüye göre daha az değer ile tanımlanabilir. Bu da siyah beyaz görüntüler üzerinde işlem yapılmasını kolaylaştırır. Örneğin, RGB modeline sahip görüntü piksellerinde işlem yapılmak istendiğinde, her piksel için kırmızı, yeşil ve mavi olarak ayrı ayrı değerler hesaplanır. Bu RGB görüntü piksellerindeki kırmızı, beyaz ve mavi değerler toplanıp üçe bölünüp her piksele bu ortalama değer atanarak renkli görüntü siyah beyaz görüntüye çevrilebilir. Böylece siyah beyaz görüntülerde her bir piksel üç değer yerine bir değer ile belirlenmiş olur ve bu durum görüntü işlemede daha hızlı işlem yapılabilmesini sağlar.

Yüz üzerindeki bazı alanların yatay veya dikey çizgilere, bazı alanlarınsa köşe noktalarına benzediği fikrine dayanarak Viola ve Jones (2001), köşe ve çizgi özellikleri içeren faklı kombinasyonlardaki siyah-beyaz dikdörtgenlerden oluşan haar benzeri özellikleri (haar like features) yüz üzerinde gezdirmişler ve yüz görüntülerinde bu özelliklerden hangilerine rastlandığını araştırmışlardır. Bu şekilde, yüz için haar peş peşe sınıflandırıcı (haar cascade classifier) ile sistem eğitimi için bir metodoloji sunmuşlardır. Yüz bölgesi için eğitilmiş veriler kullanılarak, yüz bölgesinde en çok bulunan haar benzeri özellikler görüntü içinde aranır, görüntüde yüzün olup olmadığı tespit edilir ve yüz bölgesinin sınırları belirlenir. Görüntü içindeki yüz küçük veya büyük olabileceğinden, haar benzeri özellikler farklı ölçülere getirilerek görüntü üzerinde gezdirilir. Bu işlemlerin, normal şartlarda yapılması çok yüksek zaman gerektirir ve gerçek zamanlı olarak yüz tespiti sağlamaz. Viola ve Jones, makalelerinde bu durum için de çözüm geliştirerek integral görüntü algoritmasını sunmuşlardır. İntegral görüntülerine değer atamak için görüntü üzerinde sol üst köşeden başlanarak aşağıya piksel piksel gezilir. Görüntüdeki her pikselin sol ve üstünde kalan dikdörtgen alanının içindeki pikseller toplanır ve integral görüntüsündeki her piksele bu toplam değeri atanır. Böylece, farklı boyutlarda dikdörtgenler görüntü üzerinde gezdirilirken, taranan alandaki toplam piksel değerinin hesaplanması için, tüm piksellerin toplanmasına gerek kalmadan 
işlem yapılabilir. İstenen alandaki toplam piksel değerini bulmak için integral görüntüsündeki sadece dört piksel değeri kullanılmakta ve sonuçta gerçek zamanlı olarak görüntüdeki yüzler tespit edilebilmektedir. Aynı metodoloji kulak, göz, ağız gibi yüzün farklı bölgeleri için de kullanılmaktadır. Bulunmak istenen objeyi içeren ve içermeyen çok sayıda etiketli görüntülerde haar benzeri özellikler taranmakta, bulunmak istenen objenin olduğu görüntülerde daha çok rastlanan haar benzeri özellikler tespit edilerek sistem eğitilmektedir. Haar benzeri özellikler ile haar peş peşe sınıflandırıcı algoritması kullanılarak yüz veya herhangi bir obje bulunmaya çalış1lırken, eğer taranan alanda eğitimde en çok bulunan özellik varsa, eğitimdeki bir sonraki en çok bulunan özellik aranmaya başlanır. Diğer yandan aranan özellik taranan alanda yoksa, bu alanda aranan objenin olmadığı düşünülür ve taramaya bir sonraki alanla devam edilir (Soo, 2016).

Çalışmada OpenCV kütüphanesinin Visual Studio ortamına taşınmasıyla oluşturulan EmguCV kütüphanesinden, yüz tespit ve yüz tanıma işlemlerinde faydalanıldı. Ayrıca yüzün tespit edilmesinde yüze göre doğru tespit oranı daha yüksek çıkan göz tespit sınıflandırıcıları kullanılmış ve aynı yüze ait olduğu belirlenen iki göz görüntüsüne göre yüz alanı oluşturulmuştur (Ediz, 2020).

\section{EĞITTIM VE TEST AŞAMALARI}

Yüz görüntü tespitinden sonraki adım ünlü yüz görüntüleri arasından kameradan elde edilen yüz görüntüsüne en yakın olan yüzü bulmaktır. Bu işlem için çalışmada seçilen yöntemin temeli Temel Bileşenler Analizine (TBA'ya) dayanmaktadır. TBA ile özvektörler ve özdeğerler kullanılarak boyut düşürme işlemi yapılır. TBA'daki hesaplamanın daha az elemanla yapılabilmesi için Turk ve Petland (1991) tarafindan özyüz yöntemi geliştirilmiştir. Çalışmada da, özyüz yöntemine dayalı EmguCV kütüphanesinde yer alan "EigenFaceRecognizer" metodu kullanılmıştır. Bu yöntemde kameralardan elde edilen yüz görüntüsü ile eğitimlerde girilen yüz görüntülerinin yeni boyutlarındaki izdüşümleri ve birbirleriyle olan uzaklıkları hesaplanmakta ve en küçük uzaklığa sahip yüz görüntüsü bulunmaktadır.

"EigenFaceRecognizer" metodunda yüz görüntülerinin eğitilebilmesi ve birbiriyle karşılaştırılabilmesi için aynı boyutlara getirilmesi gereklidir. Elde edilen yüz görüntüleri bu çalışmada 128 piksel genişliğinde ve 150 piksel yüksekliğinde olacak şekilde ölçeklendirilmiştir. Böylece bütün yüz görüntülerinin aynı piksel numaralarına sahip olması sağlandı. Ünlü yüzlerinin elde edilmesi için ise "Kinship Verification Dataset" kullanıldı (Fang vd., 2010). Bu veri setinde ünlü kişilere ait ebeveyn ve çocuk görüntüleri ayrı ayrı dosyalarda bulunmaktaydı. Bu iki dosyadaki daha çok tanınırlığı olan ebeveyn ve çocuklar seçilerek birleştirilmiş, seçilen bu kişiler kız ve erkek olarak gruplanmış ve her grup ayrı ayrı eğitim için kullanılmıştır. "Kinship Verification Dataset" indeki görüntülerden seçilen bayanlara ait görüntü sayısı 5 ve erkeklere ait görüntü sayısı 8 adettir. $\mathrm{Bu}$ nedenle hesaplama sonraları elde edilen öznitelik sayıları bu rakamlarla sınırlı kalmıştır.

Çalışmada, kız ve erkek gruplarına ayrılan ünlülere ait yüzlerin eğitilmesi için her iki gruba aşağıdaki adımlar uygulanmıştır:

• Ünlülere ait görüntüler siyah-beyaz görüntülere dönüştürülür ve daha sonra bu görüntülerdeki gözler tespit edilerek gözlere göre ölçeklenmiş yüz görüntüleri elde edilir.

- Eğitimde kullanılacak veri setindeki her ölçeklenmiş yüz görüntüsüne ait değerler vektör olarak yazılır ve tüm vektörler toplanıp görüntü sayısına bölünerek ortalama yüz vektörü elde edilir.

• Her yüz görüntüsü vektörünün ortalama yüz vektöründen farkı alınarak, her yüze ait fark vektörü oluşturulur.

- Fark vektörlerinden oluşan matrisin kovaryans matrisi hesaplanır.

- Kovaryans matris kullanılarak öz vektör ve öz değerler hesaplanır. 
- Yüksek öz değere sahip öz vektörlerin transpozu ile fark vektörlerinden oluşan matris çarpılarak her yüz görüntüsüne ait izdüşüm değerleri hesaplanır (Kerkül vd., 2018).

Test aşamasında ise şu işlemler yapılır (Figür 1):

- Kameradan elde edilen görüntünün siyah-beyaz görüntüye dönüşüm sonrasında yeni görüntüde gözler tespit edilir ve gözlere göre ölçeklendirilmiş yüz sınırları çizilerek test yüz görüntüsü oluşturulur,

• Test görüntüsü vektörünün ortalama yüz vektöründen farkı alınır,

•Öz vektörlerden oluşan matrisin transpozuyla test görüntüsüne ait fark vektörü çarpılır ve böylece test vektörünün izdüşüm değerleri alınmış olur.

- Test görüntüsüne ait izdüşüm değerleriyle, eğitilen yüzlere ait izdüşüm değerlerinin öklid uzaklıkları hesaplanır. Test görüntüsüne en yakın bulunan yüz görüntüsü belirlenir.

Figür 1: Yüz görüntülerinin elde edilmesine dair akış şeması

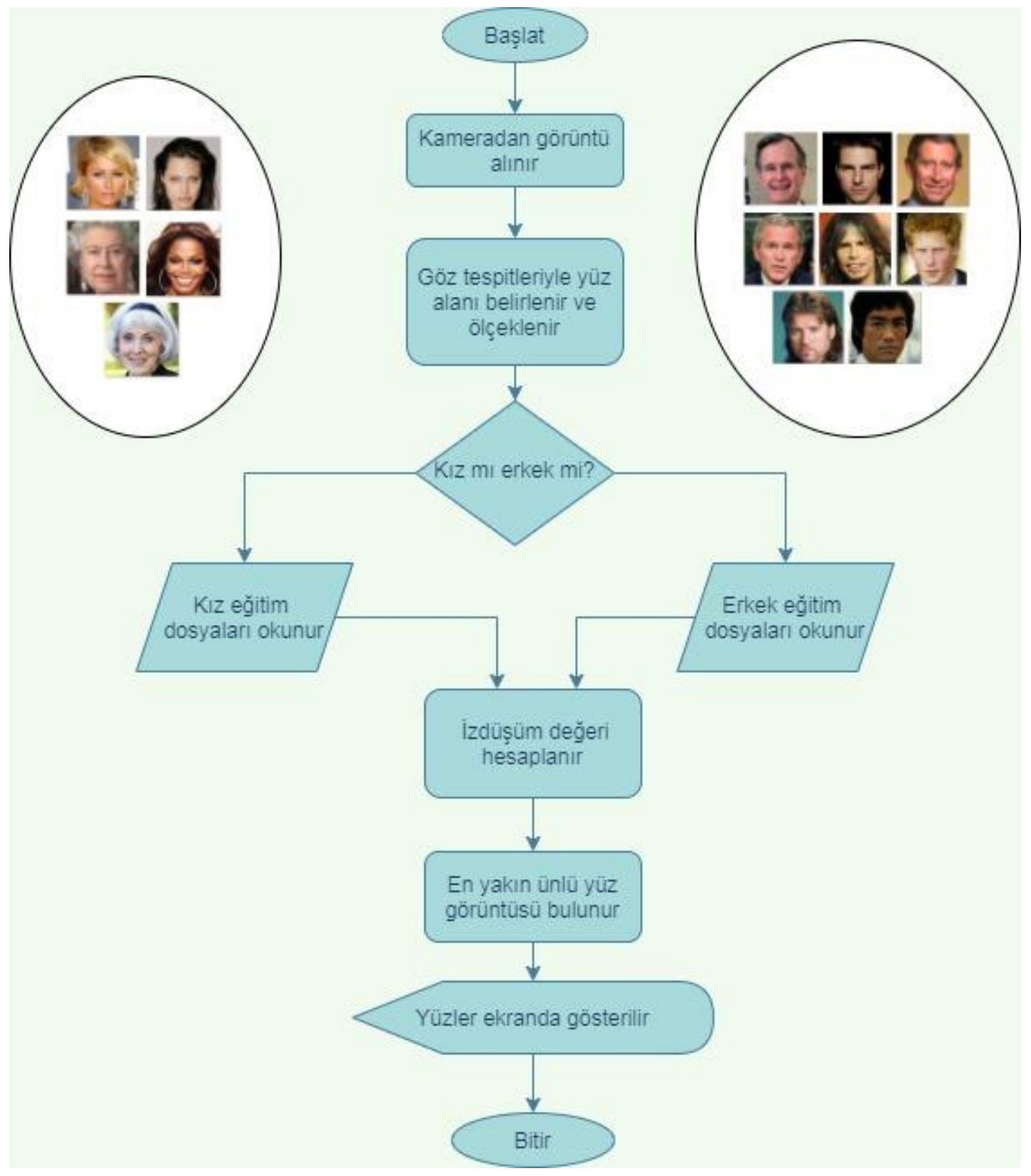




\section{KARŞILAŞTIRMA BULGULARI}

Eğitim amaçlı kullanılan görüntüler aynı zamanda kendilerine verilen kimlik numaraları ile adlandırılarak arşivlenmiştir. Böylece, "EigenFaceRecognizer" metodu sonucunda en yakın olarak elde edilen kimlik numarası kullanılarak, en yakın ünlüye ait görüntü daha önce hazırlanmış bulunan arşivden ekrana getirilmektedir. Aynı zamanda girdi olarak kullanılan yüz görüntüsü de ekranda gösterilmektedir. Son aşama olarak, görüntü işleme yöntemi ile aynı büyüklüklerde tanımlanmış olan bu iki görüntü birleştirilmektedir. Birleştirme işleminde, bir satır girdi görüntüsündeki ve bir satır çıktı görüntüsündeki piksel değerleri yeni görüntüye atanmış ve böylece bir ara yüz görüntüsü elde edilmiştir. Akademik çalışmalar için kullanıma izin verilen "Kinship Verification Dataset" veri setindeki görüntülerden seçilen görüntü sayıları düşük olmasına rağmen, test aşamasında ortaya çıkan ara yüz görüntüleri bir insan yüzü olarak kabul edilebilecek görüntüler olduğu görülmüştür (Figür 2, Figür 3 ve Figür 4).

Figür 2: Ünlü bayan yüz görüntüleri arasından en yakın görüntünün bulunduğu ekran görüntüsü

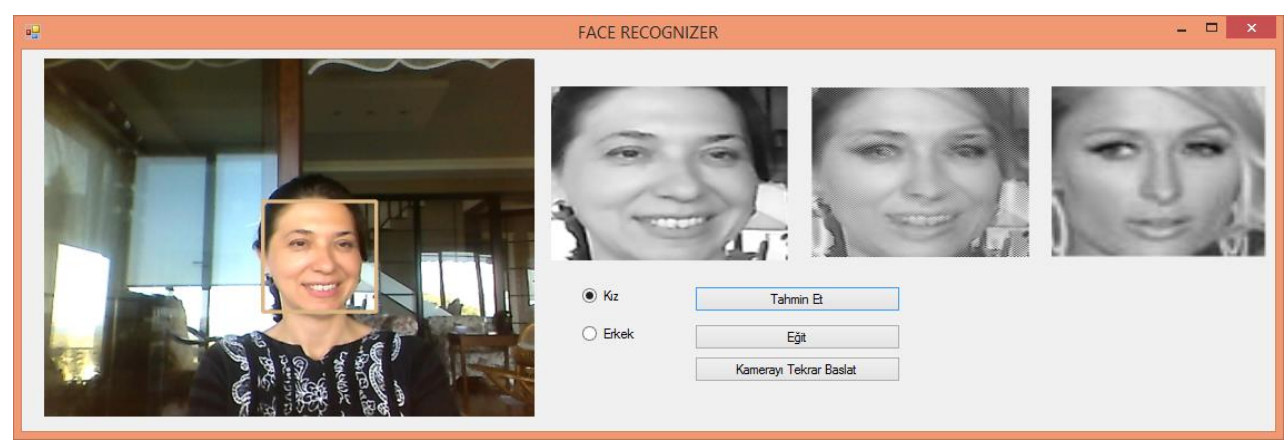

Bu çalışmada eğitim amaçlı kullanılan görüntüler çok az adetlerde olmasına rağmen, aynı kişiye ait yüz görüntüsü farklı bir mimikle veya perspektifte girildiğinde benzerlik farklı bir ünlü kişiyle olabilmektedir (Figür 3).

Figür 3: Aynı kişiye ait yüz görüntüsündeki mimik ve perspektif değişiminin sonucunda çıktı görüntüsünün değişmesi

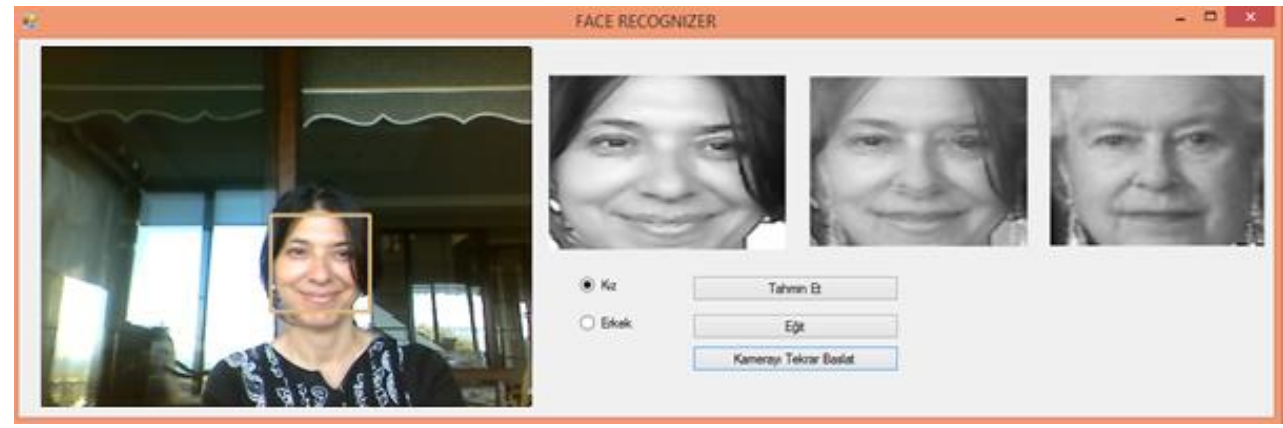

Aynı kişiye ait yüz görüntüsüne en yakın ünlü erkek yüz görüntüsü bulunmak istendiğinde, bayanlara ait eğitim dosyası yerine erkeklere ait eğitim dosyasındaki veriler ile girdi olan yüz görüntüsü karşılaştırılmaktadır. Sonrasında erkeklere ait olarak arşivlenen görüntülerden, girdiye en yakın tespit edilen ünlü yüz görüntüsü ekrana getirilmektedir (Figür 4). 
Figure 4: Ünlü erkek yüzlere ait eğitim verilerinin kullanılması ve girdi yüze en yakın erkek ünlünün bulunmas1

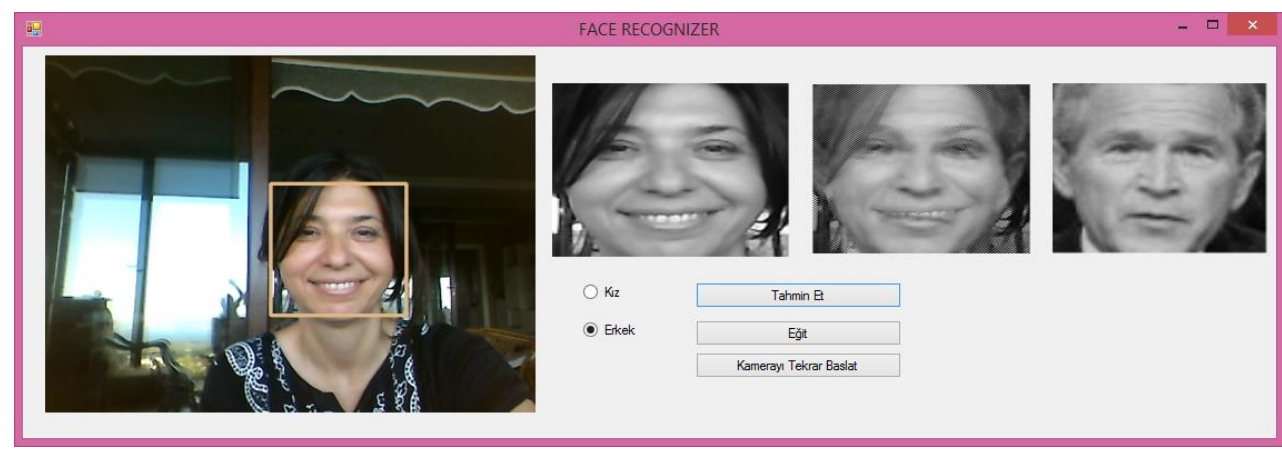

\section{SONUÇ}

Müşterilerin tercihleri için alternatiflerin bollaştığı günümüz dünyasında, müşterilerin ürüne dikkatini çekmek, kısa bir sürede istenen mesajı müşteriye iletmek önem arz etmektedir. Müşteriye kısa sürede istenen mesajı vermek için gerçek zamanlı verilere ulaşmak, onları anlık sayılabilecek bir zaman dilimi içinde onları değerlendirmek ve aynı zaman diliminde kişiselleştirilmiş sonuçları onlara sunmak için yapay zekaya dayalı algoritmaların kullanımı gittikçe yaygınlaşmaktadır. Bu çalışmada da, yapay zeka algoritmalarının kullanıldığı kişiselleştirilmiş bir eğlence uygulama metodolojisi sunulmaktadır.

Çalışmada girdi olarak verilen yüz görüntüsünün özyüzler metodu kullanılarak indirgenmiş boyut değerleriyle, kendisine en yakın eğitim görüntüsünün özyüzler metodu kullanılarak indirgenmiş boyut değerleri arasındaki uzaklık değerleri hep 3000'den fazla çıkmıştır. Normal bir yüz tanıma işlemi için bu kimlik tanıma eşiğinin üzerinde kalan bir değerdir. Ancak çalışmada yüze dayalı kimlik tespiti yapmak yerine eğlenceli bir uygulama geliştirmek hedeflendiğinden bir eşik değerinin olması istenmemiş, bu nedenle eşik değeri sonsuz olarak girilmiştir. Çalışmada kullanıcının butona basmasından sonra görüntülerin ekrana gelmesine kadar olan toplam işlem süresi ise 250 ile 400 milisaniye (Intel® Core $^{\mathrm{TM}} \mathrm{i5}-4440 \mathrm{M}$ CPU @ 3.10GHz) arasında değerler almaktadır. Bu süre değerlendirildiğinde kullanıcının çok fazla beklemediği, anlık sayılabilecek bir zaman aralığında hangi ünlüye benzediğini görebildiği görülmektedir.

Telif hakkı düşünülerek akademik çalışmalarda kullanıma izin verilen ve Türkiye'de tanınırlığı olan ünlü yüz görüntüleri kullanıldığından, az sayıda ünlü yüz görüntüsü ile çalışma gerçekleşmiştir. Buna rağmen test için elde edilen ara yüzler gerçeğe yakın görüntüler oluşturabilmiştir. Gelecekte, siyah beyaz görüntüler yerine renkli görüntüler sunularak uygulamanın görselliği artırılabilir. Ayrıca kullanıcıların farklı dijital platformlardan hareketlerinin izlenmesi sonucunda elde edilen büyük veri kullanılarak, önceki beğenileri doğrultusunda sonuç üretecek algoritmalar sunulan metodolojiye eklenebilir. Çalışmada, ünlülere ait yüzler benzetme amacıyla kullanılmış olsa da aynı yöntem hayvanlar, yaşlı insanlar, nesneler gibi farklı varlıklara benzetme uygulamalarında da kullanılabilir.

\section{KAYNAKÇA}

Bozkurt, Y. (2016). Reklamcılığa Yönelik Yeni Bir Bakış Açısı: Takyonlar, Üstgerçeklik Ve Reklam İlişkisi Üzerine Kuramsal Bir Değerlendirme. Karadeniz Teknik Üniversitesi İletişim Araştırmaları Dergisi, 6(1), 74-85. 
Ediz, Ç . (2020). Adding Virtual Objects to Realtime Images; A Case Study in Augmented Reality. Sakarya University Journal of Computer and Information Sciences , 3 (3), 188-200 .

Erkılıç, H., Dönmez, S. (2016). Sanal Gerçeklik Anlatısının İzini Sürmek: Trinity VR ve Selyatağı VR Örnekleri . SineFilozofi , Özel Sayı (2) Mayıs 2020 , 318-344.

Fang, R., Tang, K.D., Snavely N. , Tsuhan C. (2010, September). Towards Computational Models Of Kinship Verification. IEEE International Conference on Image Processing, Hong Kong.

Kekül, H., Bircan, H., Arslan, H. (2018). Yüz Tanıma Uygulamalarında Özyüzler Ve Yapay Sinir Ağlarının Karşılaştırılması. Uluslararası Yönetim Bilişim Sistemleri Ve Bilgisayar Bilimleri Dergisi, 2(1), 51-59.

Kotler, P., Kartajaya, H., Setiawan, I. (2016). Marketing 4.0: Moving From Traditional To Digital. John Wiley \& Sons.

Li, C., Zhu, F., Su, R. (2014). New Similarity Measure with Deformation Detection of Visual Salient Regions for Image Retargeting. International Journal of Multimedia and Ubiquitous Engineering, 9(7), 1-14.

OpenCV, https://docs.opencv.org/2.4/modules/contrib/doc/facerec/facerec_tutorial.html\#id16; erişim: 9.8.2020.

Özbay, G. (2020).Yiyecek İçecek Sektöründe Postmodern Pazarlama Yaklaşımı Olarak Üstgerçeklik Uygulamalarına İlişskin Bir Değerlendirme. Journal of Tourism Intelligence and Smartness, 3(1), 53-71.

Sherman, R. W. , Craig, A.B. (2019). Understanding Virtual Reality. Cambridge, USA: Morgan Kaufmann

Soo, S. (2014). Object Detection Using Haar-Cascade Classifier. Institute of Computer Science, University of Tartu, 1-12.

Şener, N. K. (2016). Eğlencenin Gözetleme Hâli Ya Da Eğlence Endüstrisinde “Görünen” Ve "Gören" Olmak. TRT Akademi, Eğlence Endüstri Sayısı, 1(1), 50-70.

Taşçi, G., \& Çelebi, M. (2020). Eğitimde Yeni Bir Paradigma:"Yükseköğretimde Yapay Zekâ". OPUS Uluslararası Toplum Araştırmaları Dergisi, 16(29), 2346-2370.

Turk, M., Pentland, A. (1991, January). Face Recognition Using Eigenfaces. In Proceedings. 1991 IEEE Computer Society Conference On Computer Vision And Pattern Recognition (586587).

Türker, İ. H. (2005). İmgeden Sanal Gerçekliğe. Anadolu Sanat Dergisi, 16(6), 1-8.

Varol, S. F. (2012). Kitle İletişim Araçlarındaki Eğlence İçeriklerine İlişkin Kuramsal Yaklaşımlar Hakkında Bir Değerlendirme. İstanbul Üniversitesi İletişim Fakültesi Dergisi| Istanbul University Faculty of Communication Journal, (43), 141-161.

Viola, P., Jones, M. (2001, December). Rapid Object Detection Using A Boosted Cascade Of Simple Features. In Proceedings of the 2001 IEEE Computer Society Conference On Computer Vision And Pattern Recognition. CVPR 2001 (Vol. 1, pp. I-I). IEEE. 